\title{
A INFLUÊNCIA DO ENSINO DO EMPREENDEDORISMO NO POTENCIAL EMPREENDEDOR DO ALUNO ${ }^{1}$
}

\section{THE INFLUENCE OF THE EDUCATION OF THE EMPREENDEDORISMO IN THE ENTERPRISING POTENTIAL OF THE PUPIL}

\author{
Kátia de Almeida ${ }^{2}$ \\ Silvestre Prado de Souza Neto ${ }^{3}$ \\ Alessandra Quintella Nunes ${ }^{4}$ \\ Marinês Sttefanello ${ }^{5}$
}

\begin{abstract}
RESUMO: O objetivo principal deste artigo é apresentar uma pesquisa desenvolvida em duas Universidades do Estado do Rio de Janeiro: uma Universidade Pública no Município de Seropédica e uma Universidade Privada no Município de Barra Mansa. A pesquisa visa avaliar a influência do ensino do Empreendedorismo no Curso de Administração no potencial empreendedor dos alunos dessas Universidades. Muito se tem estudado e discutido no mundo acadêmico, sobretudo nas últimas décadas, a respeito da importância do Empreendedorismo. A variável que serviu de comparativo e base para se atingir os principais objetivos da pesquisa estava na pergunta: - Pretende empreender quando terminar o curso? Onde 40,2\% dos entrevistados da UFRuralRJ e $62,4 \%$ dos entrevistados da UBM responderam que sim. Através da Análise de Discriminante foi concluído que, o ensino técnico do Empreendedorismo fez muita diferença no espírito empreendedor. A técnica é muito importante e nessa área o Curso de Administração parece estar cumprindo o seu papel. Porém, o ensino do Empreendedorismo só despertou o desejo de empreender em quem já tinha condições sociais e culturais favoráveis. A formação de empreendedores, no entanto, é conseqüência de indutores culturais, sociais, políticos e educacionais.
\end{abstract}

PALAVRAS-CHAVE: Empreendedorismo, Ensino Universitário, Potencial Empreendedor

ABSTRACT: The objective of this paper is to argue the efficiency of the education of the Entrepreneurship in Business Schools. The text detaches the importance of the Entrepreneurship for development, jobs generation and the consequent formation of demand through the increase of the population purchasing power. A historical profile of the education of Entrepreneurship in Brazil is traced. The research, carried through a questionnaire, with business students of the Universidad Federal Rural do Rio de Janeiro and Universidade Privada de Barra Mansa, it looks for to establish if it exists a parallel between the education of disciplines of Entrepreneurship and the students will to undertake.

KEY WORDS: Entrepreneurship, Business Schools.

\footnotetext{
${ }^{1}$ Artigo publicado no EnEPQ - I Encontro de Ensino e Pesquisa em Administração e Contabilidade - Recife / PE - 21 a 23 de novembro de 2007.

Artigo Recebido em 16.10.2008. Revisado por pares em 20.10.2008. Recomendado em 17.11.2008 por Denise Del Pra Netto Machado (editora). Publicado em 15.12.2008. Organização Responsável pelo periódico: Universidade regional de Blumenau - FURB - www.furb.br/rn
}

\footnotetext{
${ }^{2}$ Mestre em Ciências e Professora do Curso de Administração do Departamento de Ciências Administrativa e Contábeis - DCAC da Universidade Federal Rural do Rio de Janeiro - UFRuralRJ - katia200@terra.com.br

${ }^{3}$ Doutor em Administração e Professor do Curso de Administração do Departamento de Ciências

Administrativa e Contábeis - DCAC da Universidade Federal Rural do Rio de Janeiro - UFRuralRJ spsn@ufrrj.br

${ }^{4}$ Mestre em Ciências e Professora do Curso de Administração do Departamento de Ciências Administrativa e Contábeis - DCAC da Universidade Federal Rural do Rio de Janeiro - UFRuralRJ -

alessandra.quintella@yahoo.com.br

${ }^{5}$ Mestranda UFRGS - marines.steffanello@yahoo.com.br
} 


\section{INTRODUÇÃ̃O}

Muito se tem estudado e discutido no mundo acadêmico, sobretudo nas últimas décadas, a respeito da importância do empreendedorismo. A preocupação com a criação de pequenas empresas duradouras e a necessidade da diminuição das altas taxas de mortalidade desses empreendimentos são alguns dos motivos para o crescimento da popularidade do termo.

É oportuno, portanto, um estudo mais aprofundado a respeito do tema, tendo em vista que a maior parte dos empregos criados no país é advindo das micro e pequenas empresas. $\mathrm{E}$ na maioria das vezes, os pequenos empresários não possuem conceitos de gestão de negócios, atuando geralmente de forma empírica e sem planejamento. $\mathrm{O}$ que se reflete diretamente no alto índice de mortalidade. Chegando até a $75 \%$ para as microempresas (Pesquisa SEBRAE 2004).

As empresas sintonizadas com a modernidade demandam empregados que tragam algo a mais, empregados criativos e inovadores, que possam ajudá-las a criar diferenciais para vencer a competição no mercado. E este perfil de empregado só vai prevalecer à medida que for estimulada e posta em prática, por meio da educação, a capacitação para empreender, seja na Universidade ou em qualquer outro nível de ensino. Assim considerando, é fundamental que um maior número de Universidades comece a ministrar o ensino voltado para formar empreendedores e estabeleça incentivos nesta direção. Passando a ser, de fato e de direito, uma incubadora e estimuladora de verdadeiros empreendedores.

O objetivo principal deste artigo é apresentar uma pesquisa desenvolvida em duas Universidades do Estado do Rio de Janeiro: uma Universidade Pública no Município de Seropédica e uma Universidade Privada no Município de Barra Mansa. A pesquisa visa avaliar a influência do ensino do Empreendedorismo no Curso de Administração no potencial empreendedor dos alunos dessas Universidades.

\section{O EMPREENDEDORISMO E O ENSINO UNIVERSITÁRIO}

A relevância do estudo do Empreendedorismo é notável para o desenvolvimento sócioeconômico de qualquer país. Para Degen (1989), a riqueza de uma nação é medida por sua capacidade de produzir, em quantidades suficientes, os bens e serviços necessários para o bemestar da população.

Um relatório publicado pelo GEM (Global Entrepreneurship Monitor), em 2004, afirma que o Brasil ocupa o sétimo lugar em Empreendedorismo, dentre os 34 países listados. Todavia, há uma diferença significativa, que marca o Brasil perante alguns dos países que se encontram próximo a ele na classificação: o fator que leva o brasileiro a empreender. $O$ índice de Empreendedorismo por necessidade chega a atingir $46 \%$, fator que é preocupante, se associado aos apenas 13\% de empreendedores com nível superior e aos 30\%, que nem chegaram a concluir o ensino fundamental. É válido reforçar, então, a preocupação com o estudo do Empreendedorismo, como tentativa de reduzir a relação "empreendimento $\mathrm{x}$ necessidade" e reforçar a associação "empreendedorismo x vocação".

Segundo Ângelo (2003), a atividade empreendedora no Brasil tem as seguintes características:

- O Brasil possui um nível relativamente alto de atividade empreendedora: 13,5 em cada 100 adultos da População Economicamente Ativa (PEA) são empreendedores, colocando o país em sétimo lugar do mundo. No entanto, mais da metade deles está envolvida por necessidade e não por oportunidade;

- As mulheres brasileiras são bastante empreendedoras: a proporção é de cerca de $40 \%$, uma das maiores entre todos os 37 países participantes do levantamento; 
- A intervenção governamental possui duas facetas: tem diminuído, mas ainda se manifesta como um fardo burocrático;

- A disponibilidade de capital no Brasil é escassa. Muitos empreendedores brasileiros ainda percebem o capital como algo difícil e custoso de se obter. Para piorar, os programas de financiamento existentes não são bem divulgados;

- A falta de tradição e o difícil acesso aos investimentos continuam a ser os principais impedimentos à atividade empreendedora. Existe, assim, uma necessidade urgente de estimular as práticas de investimento no Brasil;

- O tamanho do país e suas diversidades regionais exigem programas descentralizados. As diferenças regionais de cultura e infra-estrutura também exigem uma abordagem localizada do capital de investimento e dos programas de treinamento;

- Infra-estrutura precária e pouca disponibilidade de mão-de-obra qualificada têm impedido a proliferação de programas de incubação de novos negócios fora dos grandes centros urbanos;

- Existe uma necessidade de aprimoramento no sistema educacional como um todo, o que estimulará a cultura empreendedora entre os jovens adultos. Os programas existentes têm sido percebidos como desconectados da realidade, com pouca integração à graduação e ao ensino básico;

- Não há proteção legal dos direitos de propriedade intelectual, os custos para registro de patentes no país e fora dele são altos e os mecanismos de transferência tecnológica são parcos. As Universidades ainda estão isoladas da comunidade de empreendedores.

O Brasil apresenta alto índice de desemprego, cerca de 10,8\% (segundo dados divulgados pelo IBGE, referente ao mês de abril de 2005), o que pode muito bem ser sanado com a ajuda dos empreendedores brasileiros. Infelizmente, no Brasil, o Empreendedorismo é apenas uma alternativa de sobrevivência, enquanto em outros países, trata-se da característica do povo.

De acordo com Dolabela (2003) o problema é que ainda não entendemos o conceito, e não sabemos passar do estágio amador para um estágio onde o Empreendedorismo seja encarado como uma prática que pode ser aprendida e deve, acima de tudo, ser ensinada. Nesse contexto a Universidade assume um papel fundamental, ficando responsável por criar e preparar os empreendedores, dando a eles o conhecimento e o suporte adequados. É preciso mostrar as ferramentas que auxiliem no alcance do sucesso e conseqüentemente contribuem para o crescimento econômico do país. Mas isso não é o que acontece na maioria das Universidades.

Para Dolabela (1999) é de fundamental importância o estímulo ao Empreendedorismo diante do decréscimo contínuo de postos de trabalhos no mundo inteiro. Devendo, este tema, ser apresentado desde os primeiros níveis da educação. Uma das soluções encontradas no sistema educacional é a oferta de cursos e matérias de Empreendedorismo, como uma alternativa, principalmente aos jovens profissionais (DORNELAS, 2001). Hall (2001) concorda quando afirma que as principais competências, para começar e construir um negócio de sucesso, podem ser desenvolvidos como parte de um aprendizado.

Para Batista (2004), o ensino de Empreendedorismo nos cursos de graduação de Administração vem restringindo sua abordagem predominantemente ao desenvolvimento de planos de negócios como uma ferramenta gerencial de validação de idéias de novos negócios. A disciplina tem o objetivo de gerar novos negócios e de reduzir os fracassos na sua implementação.

Para Leite (2002) a educação empreendedora nos Cursos de Administração seria uma solução para a falta de crédito e melhoria da gestão dos pequenos empreendimentos. Poderia incentivar os alunos a atuarem de forma independente e mais empresarial. Todavia, tem-se 
observado que, a disciplina de Empreendedorismo nos cursos de graduação em Administração não instrumentaliza os alunos com ferramentas teóricas que sustentem a prática de identificação de oportunidades.

Batista (2004) cita as dez razões que justificam o estudo do Empreendedorismo, publicadas pelo INATEL. São elas:

a. A alta taxa de mortalidade: no mundo das empresas emergentes. De cada três empresas criadas, duas fecham as portas. As pequenas empresas (com menos de cem empregados) fecham mais: $99 \%$ das falências são de empresas pequenas;

b. As relações de trabalho estão mudando. O emprego dá lugar a novas formas de participação. A tradição do nosso ensino, de formar empregados nos níveis universitário e profissionalizante, não é mais compatível com a organização da economia mundial;

c. Exige-se hoje, mesmo para aqueles que vão ser empregados, um alto grau de "empreendedorismo";

d. A metodologia de ensino tradicional não é adequada para formar empreendedores;

e. As instituições de ensino no Brasil estão distanciadas dos "sistemas de suporte". As relações Universidade-empresa ainda são incipientes;

f. Cultura: os valores do nosso ensino não sinalizam para o Empreendedorismo;

g. Ainda há uma percepção insuficiente da importância da Pequena e Média Empresa para o desenvolvimento econômico;

h. Predomina, no ensino profissionalizante e universitário, a cultura da "grande empresa". Não é hábito se falar de pequena empresa;

i. Ética: uma grande preocupação no ensino do Empreendedorismo deve estar atrelada aos aspectos éticos que envolvem esta atividade;

j. Cidadania: o empreendedor deve ser alguém com alto grau de comprometimento com o meio ambiente e com a comunidade, com forte consciência social.

\section{METODOLOGIA}

A metodologia utilizada foi uma pesquisa descritiva, com amostragem não probabilística intencional por acessibilidade e começou com a coleta de dados primários através de um questionário composto de 25 perguntas objetivas, respondido pelos alunos do Curso de Administração da Universidade Federal Rural do Rio de Janeiro - UFRuralRJ, no mês de Abril/2006, e da Centro Universitário de Barra Mansa - UBM no mês de Março/2007.

Para os alunos do Curso de Administração da UFRuralRJ, foram aplicados 250 questionários, dos quais 26 tiveram que ser eliminados por problemas de preenchimento, reduzindo, assim o tamanho da amostra para 224 respondentes. Para os alunos do Curso de Administração da UBM, foram aplicados 200 questionários, dos quais 33 tiveram que ser eliminados por apresentarem problemas no preenchimento, reduzindo, assim o tamanho da amostra para 167 respondentes. Essa redução, no entanto, não compromete os resultados obtidos pois o tamanho da amostra continua sendo suficiente para dar representatividade ao universo pesquisado, aproximadamente $20 \%$ dos alunos de todos os períodos do Curso de Administração das duas Universidades.

Os dados depois de tabulados, tiveram tratamento estatístico, segundo o método de Análise Funcional de Intercorrelações - matriz rodada de correlações, também chamado de Equamax com a Normalização de Kaiser (SPSS 1999: 410), usando o software SPSS (Statistical Package for the Social Scienses) versão10.0. A análise estatística descritiva foi seguida por uma outra multivariada conhecida como Análise Discriminante múltipla (MDA multiple discriminants analysis). 
Segundo Hair et al (2005), a Análise Discriminante múltipla permite descobrir as ligações que existem entre um caráter qualitativo a ser explicado e um conjunto de caracteres quantitativos explicativos. Também permite prever, por meio de um modelo, os valores da variável que derivem dos valores dos valores tomados pelas variáveis explicativas.

Neste trabalho a Análise Discriminante foi utilizada para identificar os grupos de empreendedores que por acaso existam entre os jovens estudantes, bem como as características principais que os identificam. O que se buscou foi entender se a Universidade estava ou não contribuindo para o desejo de empreender (caráter qualitativo), e saber quais características, dentre as analisadas, essas pessoas tinham.

O questionário utilizado foi composto por 26 perguntas divididas em duas partes distintas: treze perguntas iniciais, caracterizando os estudantes pelo seu período, idade, sexo e traçando um perfil sócio-econômico; a partir da décima quarta pergunta, todas as questões versam sobre Empreendedorismo.

\section{ANÁLISE DOS RESULTADOS}

Analisando e interpretando as respostas, foi possível identificar o período, idade, sexo e traçar um perfil sócio-econômico dos alunos.

A Tabela 1 mostra a distribuição de alunos entrevistados por período em cada uma das Universidades. Se faz necessário ressaltar que na UFRuralRJ as matérias do ciclo profissional são ministradas a partir do $5^{\circ}$ período $(42,4 \%)$, enquanto na UBM, estas começam a partir do $4^{\mathrm{o}}$ período $(64,3 \%)$.

TABELA 1 - Número de alunos por período em cada Universidade

\begin{tabular}{|c|c|c|}
\hline Período & UFRuralRJ & UBM \\
\hline $1^{\mathrm{o}}$ & $10,7 \%$ & $10,8 \%$ \\
\hline $2^{\mathrm{o}}$ & $16,5 \%$ & $10,4 \%$ \\
\hline $3^{\mathrm{o}}$ & $8,5 \%$ & $14,5 \%$ \\
\hline $4^{\mathrm{o}}$ & $21,9 \%$ & $5,5 \%$ \\
\hline $5^{\mathrm{o}}$ & $3,1 \%$ & $10,9 \%$ \\
\hline $6^{\mathrm{o}}$ & $7,6 \%$ & $5,5 \%$ \\
\hline $7^{\mathrm{o}}$ & $3,6 \%$ & $20,6 \%$ \\
\hline $8^{\mathrm{o}}$ & $17,4 \%$ & $13,4 \%$ \\
\hline $9^{\mathrm{o}}$ em diante & $10,70 \%$ & $8,4 \%$ \\
\hline
\end{tabular}

Fonte: Dados da pesquisa

A maioria absoluta dos alunos entrevistados $(82,6 \%)$ na UFRuralRJ possuem até 25 anos, enquanto na UBM esta faixa etária correspondeu a $61,8 \%$.

Quanto ao sexo, verificou-se que 52,7\% dos alunos entrevistados são do sexo feminino, em ambas as amostras.

Foram feitas perguntas sobre a renda individual, renda familiar, escolaridade do pai e da mãe e a situação no mercado de trabalho do pai e da mãe. Os dados referentes à mãe e ao pai, se mostraram muito importantes nessa análise, nas duas Universidades, conforme será visto.

A variável que serviu de comparativo e base para se atingir os principais objetivos da pesquisa estava na pergunta: - Pretende empreender quando terminar o curso? Onde 40,2\% dos entrevistados responderam que sim na UFRuralRJ e 62,4\% na UBM .

Quando questionados se: Antes da Universidade pensavam em ter seu próprio negócio? 46\% dos entrevistados da UFRuralRJ e 62,4\% dos entrevistados da UBM responderam sim. Comparando as respostas das duas perguntas, têm-se a impressão que, UFRuralRJ, o curso interferiu negativamente no desejo de empreender. No entanto, quando combinamos as variáveis, percebemos que o período em que o aluno se encontra é um fator decisivo no desejo de empreender. Na Análise Discriminante para o perfil empreendedor do 
estudante, foi constatado que, a grande maioria dos $40,2 \%$ entrevistados que respondeu sim à pergunta (Pretende montar seu próprio negócio?) estava no $5^{\circ}$ período ou à frente, quando começam a ser estudadas as matérias específicas do curso. Já na UBM, não houve diferença percentual no desejo de empreender durante o curso.

TABELA 2 - Des ejo de empreender

\begin{tabular}{|l|r|r|}
\hline & UFRuralRJ & UBM \\
\hline Pretende empreender depois de formar & $40,2 \%$ & $62,4 \%$ \\
\hline Antes da Universidade pensava em empreeder & $46,0 \%$ & $62,4 \%$ \\
\hline Fonte: Dados a pesquisa
\end{tabular}

Fonte: Dados a pesquisa

A pergunta seguinte: Já cursou a disciplina sobre Empreendedorismo na faculdade? $\mathrm{Na}$ UFRuralRJ, 43,3\% responderam sim, e desses, 58,8\% disseram que a disciplina despertou neles o desejo de empreender. Na UBM este total foi de $69,1 \%$ de alunos que já cursaram essas matérias, e em $76,3 \%$ dos alunos despertou neles o desejo de empreender.

Observa-se aqui que na UFRuralRJ, 40,2\% pretendem montar seu próprio negócio e 43,3\% já tiveram matérias sobre Empreendedorismo. Já na UBM, 62,4 pretendem montar seu próprio negócio e, 69,1 já tiveram matérias sobre Empreendedorismo. Pode-se concluir que existe um paralelo importante sobre o período, matérias sobre Empreendedorismo e o desejo de empreender. Dos 56,7\% que não tiveram ainda matérias sobre Empreendedorismo, na UFRuralRJ, que são os alunos que estão do $1^{\circ}$ ao $4^{\circ}$ período, $94,5 \%$ gostariam de aprender sobre o tema. Já na UBM, o percentual que quem não teve matérias sobre Empreendedorismo é de $30,9 \%$, em sua maioria alunos de $1^{\circ}$ ao $3^{\circ}$ período, desses $94,1 \%$ gostariam de cursar estas disciplinas. Logo, nesse universo pesquisado, o Curso de Administração interfere significativamente na decisão de empreender.

TABELA 3 - Matérias sobre Empreendedoris mo

\begin{tabular}{|l|r|r|}
\hline & UFRuralRJ & \multicolumn{1}{c|}{ UBM } \\
\hline Curs aram matérias sobre Empreendedoris mo & $43,3 \%$ & $69,1 \%$ \\
\hline Pretende empreender depois de formar & $40,2 \%$ & $62,4 \%$ \\
\hline
\end{tabular}

Fonte: Dados a pesquisa

O ensino de Empreendedorismo foi pouco relevante antes da Universidade visto que apenas $8,9 \%$ dos entrevistados na UFRuralRJ e 15,2\% dos entrevistados na UBM haviam tido matérias sobre Empreendedorismo. Ainda assim, em $60 \%$ dos alunos, da UFRuralRJ, que cursaram essa disciplina e 74\%, da UBM, foi despertado o desejo de abrir um negócio próprio. Isso vem corroborar, nesse estudo, o que Dolabela (2003) destaca em seu texto, quanto à importância de uma cultura empreendedora que deveria se iniciar no ensino fundamental.

Quando questionados sobre: Vão atuar na área em que se formaram? 72,8\% doa alunos da UFRuralRJ, e 69,7\% dos alunos da UBM, responderam que sim. Pode-se perceber que, embora na pergunta base (Pretende empreender quando terminar o curso?), na UFRuralRJ, 40,2\% e na UBM 62,4\%, tenham respondido que pretendem empreender, nessa apenas 33,8\% do total de alunos da UFRuralRJ e 33,9\% do total de alunos da UBM, optaram por essa alternativa. Pode-se concluir, que, mesmo montando um negócio próprio, 6,4\% (a diferença) na UFRuralRJ e $28,5 \%$ (a diferença) na UBM, dos que fizeram essa opção, também querem ter um outro tipo de emprego. Nessa pergunta, os $72,8 \%$ dos alunos que vão atuar na área, se dividem em: 24,6\% pretendem montar seu próprio negócio; 32,6\% pretendem trabalhar numa grande empresa; 5,4\% pretendem ser professores; $1,3 \%$ pretendem ser autônomos; $24,6 \%$ pretendem tentar concurso público e 11,6\% vão seguir outras opções na UFRuralRJ. Já na UBM, os 69,7\% dos alunos que vão atuar na área, são divididos em: 33,9\% pretendem montar seu próprio negócio; $41,8 \%$ pretendem trabalhar numa grande empresa; 
7,8\% pretendem ser professores; $1,7 \%$ pretendem ser autônomos; $14,8 \%$ pretendem tentar concurso público. Vale observar que o número de alunos do Curso de Administração que pretendem tentar concurso público, e estão se preparando para isso, vem aumentando a cada ano. Seria interessante um estudo para analisar essa tendência

TABELA 4 - Área profissional

\begin{tabular}{|l|r|r|}
\hline & UFRuralRJ & \multicolumn{1}{c|}{ UBM } \\
\hline Pretende empreender depois de formar? & $40,2 \%$ & $62,4 \%$ \\
\hline Pretende ter seu próprio negócio? & $33,8 \%$ & $33,9 \%$ \\
\hline Diferença & $6,4 \%$ & $28,5 \%$ \\
\hline
\end{tabular}

Fonte: Dados a pesquisa

A questão seguinte foi: Alguém muito próximo a você possui um empreendimento? $80,8 \%$ dos alunos responderam sim, e, em praticamente $50 \%$ dessas pessoas, foi um fator que contribuiu para despertar o desejo de empreender, na UFRuralRJ. Enquanto na UBM, 86,7\% dos alunos responderam sim, e esse conhecimento em $62,2 \%$ dos alunos foi determinante no desejo de empreender. A conclusão dessa questão é respaldada pelo texto de Dolabela (1999), que diz que se alguém é muito próximo a uma pessoa possui um empreendimento é maior a probabilidade dessa pessoa ser também um empreendedor. Segundo o autor, aprende-se a ser empreendedor pela convivência com outros empreendedores, em um clima em que ser dono do próprio nariz, ou seja, ter seu próprio negócio e ser seu próprio patrão, é algo muito positivo e estimulante. Vemos, então, que o total de entrevistados que foram estimulados por uma pessoa muito próxima a eles, foi de $41,5 \%$ na UFRuralRJ, e 53,9\% na UBM, o que é muito significativo em relação ao total que deseja empreender, que foi de $40,2 \%$ e $62,4 \%$, respectivamente. Pesquisas indicam que as famílias de empreendedores têm maior chance de gerar novos empreendedores e que os empreendedores de sucesso quase sempre têm um modelo, alguém a quem admiram e imitam (Fillion, 1991).

Por último tivemos a pergunta: Sente-se a vontade como empregado ou empregador? Apenas 33,5 \% dos entrevistados da UFRuralRJ e 31,5 dos entrevistados da UBM, responderam que se sentiriam a vontade com empregados. O que deduzimos é que muitos que não querem ser empregados $(76,5 \%-40,2 \%=36,3 \%$ na UFRuralRJ e $68,5 \%-62,4 \%=6,1 \%$ na UBM) não pensam em empreender por outros motivos. É uma questão intrigante, essas pessoas não querem ser empregados e não querem ser patrões. O que eles vão fazer? Uma das razões, que pode ser muito forte, é a cultura empreendedora não estimulada no Brasil. Na educação do país o errar é proibitivo, seja na escola, em casa, na religião etc. Quem não erra não aprende a ser criativo, quem não cria não inova, não se formam líderes nem empreendedores (Dolabela, 2002). Logo, não estamos aprendendo a ser empreendedores na sociedade brasileira em geral.

TABELA 5- Empregado ou Empregador?

\begin{tabular}{|l|r|r|}
\hline & UFRuralRJ & \multicolumn{1}{c|}{ UBM } \\
\hline Sente-se à vontade como empregador & $76,5 \%$ & $68,5 \%$ \\
\hline Pretende empreender depois de formar & $40,2 \%$ & $62,4 \%$ \\
\hline Diferença & $36,3 \%$ & $6,1 \%$ \\
\hline
\end{tabular}

Fonte: Dados a pesquisa

Na Análise Discriminante para o perfil empreendedor do estudante, como mostra a Tabela 6, a amostra total foi dividida em grupos baseados na variável dependente pretende empreender quando terminar o curso.

$\mathrm{Na}$ UFRuralRJ, o período foi a variável que mais se relacionou à iniciativa empreendedora. Quanto maior o período, maior no número de alunos que manifestaram a postura empreendedora. Em seguida, vieram duas variáveis: escolaridade da mãe e situação da mãe no mercado. Depois do período, os grupos de alunos que queriam empreender eram 
os que a mãe possuía maior escolaridade, e em seguida os que a mãe era mais bem posicionada no mercado de trabalho.

$\mathrm{Na}$ UBM, em primeiro lugar, a variável que mais se relacionou à iniciativa empreendedora foi a escolaridade da mãe. Em segundo, apareceu a variável situação do pai no mercado de trabalho e, em terceiro, o período.

TABELA 6 - Variáveis discriminantes a análise de fatores que incentivam a empreender

\begin{tabular}{|c|c|c|r|r|r|r|r|r|}
\hline \multirow{2}{*}{ Step } & $\begin{array}{c}\text { Variáveis } \\
\text { UFRuralRJ }\end{array}$ & $\begin{array}{c}\text { Tolera } \\
\text { nce }\end{array}$ & $\begin{array}{c}\text { F to } \\
\text { remove }\end{array}$ & $\begin{array}{c}\text { Wilk's } \\
\text { Lambda }\end{array}$ & $\begin{array}{c}\text { Variáveis } \\
\text { UBM }\end{array}$ & $\begin{array}{c}\text { Tolera } \\
\text { nce }\end{array}$ & $\begin{array}{c}\text { F to } \\
\text { remove }\end{array}$ & $\begin{array}{c}\text { Wilk's } \\
\text { Lambda }\end{array}$ \\
\hline 1 & Período & 1,000 & 166,037 & 0,000 & Es colaridade mãe & 1,000 & 57,338 & 0,000 \\
\hline 2 & Período & 0,948 & 174,062 & 0,575 & Es colaridade mãe & 1,000 & 56,678 & 0,685 \\
\hline & Escolaridade mãe & 0,948 & 58,553 & 0,306 & Situação merc pai & 1,000 & 24,348 & 0,483 \\
\hline \multirow{2}{*}{3} & Período & 0,933 & 176,972 & 0,437 & Es colaridade mãe & 0,989 & 56,913 & 0,480 \\
\cline { 2 - 10 } & Escolaridade mãe & 0,942 & 53,055 & 0,220 & Situação merc pai & 0,955 & 26,894 & 0,349 \\
\cline { 2 - 10 } & Situação merc mãe & 0,982 & 24,437 & 0,170 & Período & 0,944 & 22,955 & 0,332 \\
\hline \multirow{2}{*}{4} & Período & 0,931 & 173,781 & 0,343 & Escolaridade mãe & 0,976 & 27,561 & 0,265 \\
\cline { 2 - 9 } & Escolaridade mãe & 0,824 & 18,058 & 0,126 & Situação merc pai & 0,948 & 24,451 & 0,254 \\
\cline { 2 - 9 } & Situação merc mãe & 0,930 & 29,154 & 0,141 & Período & 0,908 & 25,566 & 0,258 \\
\cline { 2 - 9 } & Es colaridade pai & 0,815 & 18,943 & 0,127 & Escolaridade pai & 0,930 & 17,558 & 0,232 \\
\hline
\end{tabular}

Fonte: Dados a pesquisa

Em ambas as Universidades, a quarta variável que mais se relaciona com o desejo de empreender foi a escolaridade do pai.

$\mathrm{O}$ que mostra a influência do fator cultural e social no Empreendedorismo. Na sociedade brasileira a influência da mãe na educação do filho é muito grande, fator que poderia explicar essa tendência. Mas, a mãe, que agora influencia o filho, não é a mãe que fica em casa o dia todo. Essa mãe trabalha, está atuante no mercado de trabalho, é, na essência, uma mulher moderna e, ainda assim, exerce uma forte influência em sua formação. O pai bem posicionado no mercado de trabalho também exerce uma forte influência.

O período aparece como a variável mais relacionada numa Universidade e a terceira na outra, isso mostra a influência da faculdade de Administração no Empreendedorismo dos entrevistados.

\section{CONCLUSÃO}

O Empreendedorismo tem-se se apresentado como solução de muitos problemas da economia atual, pois atua como agente influenciador da geração de novas empresas, passando a ser a opção mais viável para a criação de novos postos de trabalho e tornando-se, por conseguinte, a origem da intensificação das transações econômicas e da competitividade de uma nação.

O desenvolvimento sócio-econômico é uma função da pujança industrial que está relacionada à qualidade técnica dos empreendedores. A Universidade e, especialmente, o Curso de Administração, têm importante impacto sobre aquele desenvolvimento. É o Curso de Administração que apresenta maior afinidade com o universo dos negócios, base primeira para a transformação da sociedade.

Conclui-se, pela análise dos dados neste estudo, que nessa pesquisa, o ensino técnico do Empreendedorismo fez muita diferença no espírito empreendedor. A técnica é muito importante e nessa área o Curso de Administração parece estar cumprindo o seu papel.

Porém, o ensino do Empreendedorismo só despertou o desejo de empreender em quem já tinha condições sociais e culturais favoráveis. A formação de empreendedores, no entanto, é conseqüência de indutores culturais, sociais, políticos e educacionais (Pantzier, 1999). 
Uma parcela dos alunos dos Cursos de Administração, de ambas as Universidades, têm feito essa opção para adquirirem conhecimentos que lhes possibilitem desenvolver seu próprio negócio, porém ainda é muito grande o número de alunos que fazem o curso para buscar colocação em empresas já estabelecidas ou para prestarem concurso público, e não para partirem para uma empreitada própria.

A maioria dos entrevistados, na UFRuralRJ, não pensa ainda em empreender, e é necessário, para isolar a variável período, repetir essa pesquisa, futuramente, somente com esses alunos quando estes estiverem cursando do $5^{\circ}$ período em diante, onde já se tem matérias de empreendedorismo. Já na UBM, como essas matérias começam a partir do $4^{\circ}$ período, notou-se uma porcentagem expressivamente maior ( $22,2 \%$ ) que querem empreender depois de formar. Para isolar essa variável nessa Universidade, recomenda-se que se repita a pesquisa apenas com alunos do $4^{\circ}$ período em diante. Um fato que poderia estar interferindo nessa diferença, além do período, é a faixa etária dos alunos entrevistados. Enquanto na UFRuralRJ $17,4 \%$ tem mais que 25 anos, na UBM esse percentual é de $38,2 \%$.

Os Cursos de Administração podem ser excelentes veículos de preparação de profissionais com características empreendedoras. Para tanto é fundamental que se atente para a importância da formação de empreendedores e que os alunos entendam o Empreendedorismo, para que possam colaborar no aperfeiçoamento dos instrumentos de estímulo ao desenvolvimento de empreendedores.

Nesta pesquisa percebe-se que o Curso de Administração da UFRuralRJ cumpre uma parte do ensino de Empreendedorismo, porém, não forma empreendedores. Na UBM, embora o percentual de alunos que desejam empreender seja maior, quando analisado quem pretendia depois de formar ter apenas um negócio próprio como fonte de renda, percebeu-se que esse percentual foi muito baixo. $\mathrm{O}$ ensino universitário carece de ferramentas que estimulem o estudante a empreender, e ainda, o que se observa são métodos antiquados e técnicas operacionais que em nada contribuem para o desenvolvimento do Empreendedorismo.

Como o Empreendedorismo não é uma técnica, mas uma experiência total de vida, a formação de uma pessoa empreendedora é o resultado de ações econômico-culturais e da escola. Poder-se-ia pensar, num esforço conjunto, de cursos de graduação em Administração, incubadoras de empresas, políticas públicas de criação de facilidades legais e ações articuladoras de outras organizações sociais com o objetivo de estimular a criação de novos empreendimentos.

É necessário a implementação de novas metodologias, que contenham as técnicas necessárias para o ensino do Empreendedorismo nos Cursos de Administração, bem como, que a Universidade envolva o aluno em torno do tema, estimulando nele o desejo de empreender, de maneira que a idéia se transforme em uma nova perspectiva em sua vida.

\section{REFERENCIAS}

ÂNGELO, E. B. Empreendedorismo: a revolução do novo Brasil. Revista de Economia \& Relações Internacionais. São Paulo, vol. 1, n. 2, p. 37-48, Jan. 2003.

BATISTA, C. H. Estudo Comparativo do Desenvolvimento das Características Comportamentais Empreendedoras dos Alunos da Disciplina de Empreendedorismo Durante o Primeiro Semestre Letivo de 2004 nos Cursos de Administração e Turismo \& Lazer da FURB. Dissertação de Mestrado em Administração do Centro de Ciências Sociais Aplicadas da FURB. Blumenau, 2004.

DEGEN, R. O empreendedor: fundamentos da iniciativa empresarial. São Paulo: MacGraw-Hill, 1989. 
DOLABELA, F. O segredo de Luísa. São Paulo: Cultura, 1999.

DOLABELA, F. Ensino de Empreendedorismo na Educação Básica como instrumento do desenvolvimento local sustentável. A metodologia Pedagogia Empreendedora. 2002 Disponível em: http.www.starta.com.br/informe/16/26jan05EnsinodeEmpreendedorismo.zip acessado em 17/02/2007.

DOLABELA, F. Pedagogia Empreendedora. São Paulo: Cultura, 2003.

DORNELAS, J. C. A. Empreendedorismo: transformando idéias em negócios. Rio de Janeiro: Campus, 2001.

FILION, L. J. O planejamento do seu sistema de aprendizagem empresarial: identifique uma visão e avalie o seu sistema de relações. RAE - Revista de Administração de Empresas, FGV, São Paulo, jul/set. 1991.

GEM-Global Entrepreneurship Monitor. Empreendedorismo no Brasil 2004.Disponível em: http://www.dce.sebrae.com.br/bte/bte.nsf/1EC939C7F8E5D50503256FE200487D4A/\$File/N T000A6806.pdf, acessado em 13/02/2007.

HALL, D. Na Companhia dos Heróis. Uma visão de empreendedores em ação. São Paulo: Makron Books, 2001.

HAIR, J. F. JR.; ANDERSON, R. E.; TATHAM, R. L., BLACK, W. C. Análise Multivariada de Dados. 5. Ed. Porto Alegre: Bookman, 2005.

LEITE, E. O fenômeno do Empreendedorismo criando riquezas. Recife: Edições Bagaço: 2002.

PANTZIER, R. D. Empreendedorismo e Formação de Administradores: uma análise do Curso de Administração da FURB. Dissertação Final de Mestrado em Administração do Centro de Ciências Sociais Aplicadas da FURB. Blumenau, 1999.

SEBRAE - Boletim Estatístico de Micro e Pequenas Empresas. Observatório SEBRAE, $\quad 1^{\circ} \quad$ semestre $2005 . \quad$ Disponível em: http://www.dce.sebrae.com.br/bte/bte.nsf/03DE0485DB219CDE0325701B004CBD01/\$File/ NT000A8E66.pdf. Acessado em 13/02/2007. 